\title{
REREADING FRESHMAN-YEAR BLOGS: THIRD-YEAR PRE-SERVICE STUDENT TEACHERS REVIEW THEIR FIRST-YEAR REFLECTIVE BLOGS
}

\author{
Liat Biberman-Shalev \\ Levinsky College of Education, Israel
}

\begin{abstract}
In recent years, there has been increasing evidence that the use of blogs in diverse academic contexts is becoming more commonplace, particularly in teacher education. In this context, the blog is seldom used as a study journal in which pre-service student teachers document relevant information from college courses and practical work at the school, publish reflective records, voice their opinions regarding educational issues, and express their feelings and emotions vis-à-vis academic study. Moreover, since scholars have portrayed the blog as a space where discourse can occur among learners, between learners and instructors, as well as between learners and the larger internet community, it seems that teacher education may consider blogs to serve as platforms for encouraging both online and faceto-face communication and social interaction. The current study examines student teachers' perceptions regarding the contribution of the blogs they had written earlier in the teacher education program. To this end, 14 student teachers who were about to complete their third year of studies were asked to reread their freshmen year blogs. Next, participants were interviewed about the contribution of the blog to their training. Qualitative analysis of the interviews revealed three major ways in which the blog writing assignment had affected the teacher-education process, according to their retrospective views. Specifically, these participants found that the blog writing assignment was effective for the purposes of reflection, developing writing skills, and peer learning and sharing. Recommendations for teacher-educators regarding the contribution of blogs are discussed.
\end{abstract}

Keywords: Blogs, Reflection, Writining skills, Teacher education.

\section{Introduction}

The integration of various types of blogging activities in the course of teacher-education programs has frequently been addressed through empirical studies. The majority of the research that examined the value of blog integration in the teacher-education process referred, for example, to conducting a blog during the teaching practicum, recording one's reflections after a particular experience in the field, blogging as a component of a course on peer learning, or for the purpose of encouraging 
reading (Nambiar \& Thang, 2016; Tang \& Lam, 2014; Top et al., 2010), Yukselturk \& Inan, 2010). The goal of the current study was to examine student teachers' retrospective perceptions regarding the value they attributed to the blogging activity in the teacher-education process.

\section{Literature Review}

\section{Blogs}

A blog (short for Weblog) is an Internet site in which people can keep an online journal, by logging in - or posting - their experiences, personal news, and items of interest. These posts can then be perused by Internet surfers, who are invited to read and react to the content of the posts by posting their own comments (referred to as talkbacks). Those who write and record their thoughts and experiences are called bloggers and the entire collection of blogs on the Internet is referred to as the blogosphere. There are three characteristics that are common to most blogs: they contain a chronological narrative presented in reverse order (whereby the latest blog post is the first on the page); the contents in the post are related to the blogger's real-life experiences and thoughts; and posts are updated and uploaded to the blog at regular intervals (Sim \& Hew, 2010). It is customary to classify blogs according to four dimensions: (1) personal-individual (log network: personal online diary of one blogger), (2) private-public (group support: team of bloggers discussing personal matters), (3) topically-individual (column: a blogger's personal interpretation of a new theme with each entry), and (4) topically-public (shared content: community of bloggers writing about local and global social matters) (Krishnamurthy, 2002).

All blogs share the following characteristics: individual ownership (the blogger is responsible for publishing and editing content, determining readers' rights, and designing the blog), hyperlinked post structure (the blog permits the creation of links to external information), updates displayed in reverse chronological order and the creation of an internal blog information search according to different categories and tags).

\section{The Value of Blogging in Teacher Education}

Empirical studies have demonstrated a variety of possible advantages of integrating blogs into the process of teacher education. Nonetheless, findings have not led to a decisive conclusion (Tang, 2013). On the one hand, it was found that blogging can help improve student teachers' reading, writing, and critical thinking skills, and that there is benefit to providing student teachers with this platform (Biberman-Shalev, 2018; Deng \& Yuen, 2011; Osman \& Koh, 2013; Stoszkowski \& Collins, 2017). Furthermore, 
integrating blogging activities into the teacher education process allows for flexibility in terms of the time and location in which the learning takes place, and it has been shown to increase learning satisfaction, improve academic achievements, and contribute to a more profound understanding of the materials learned, as well as offering an opportunity to share experiences with lecturers and peers (Chu et al., 2012; Kirkwood \& Price, 2014). On the other hand, there is evidence that blogging is not an effective means for advancing the teacher process, especially as this pertains to the development of higher-order reflective practices (Jones \& Ryan, 2014; Xie et al., 2008).

A few studies have indicated that blogging has a unique influence in terms of strengthening student teachers' sense of self-efficacy. Thus, for example, a study conducted in Switzerland found that student teachers who kept a blog focusing on problem solving in the course of their practicum indicated a higher degree of self-efficacy compared to their peers who reported on their experience only at the end of the practicum. Researchers' explanation for this finding was that by documenting their ideas for solving problems, student-teachers felt they had more control over the practicum experience (Petko et al., 2017).

Based on this review of the literature, it appears that the majority of studies that examined the value of blog integration in the teachereducation process referred to the use of blogs at a given point in time. Frequently, however, once the practicum or the theoretical course is over, the blog is archived and forgotten. The focus of the current study was on the student-teachers' retrospective views of the blogging experience and its contribution to their professional training. Hence, the following research question was formulated:

- From the vantage point of retrospective reflection, what were third-year student-teachers' impressions of and what value did they attribute to the blogging activity in which they partook in their freshman year?

\section{Methods}

The methodology employed in the current study was the naturalistqualitative paradigm, rendering a phenomenological, retrospective longitudinal study (Flick, 2004). This was considered the most suitable approach for examining the retrospective perceptions of student-teachers regarding the value of the blogging activity conducted in their first year in the program. Retrospective studies ask participants to look back at events and issues experienced in the past. The principal instruments used to collect data in this type of naturalistic study are interviews and conversations, documents, memos, and written logs (Creswell, 2005). 


\section{Background of the Study}

The study was conducted in a teacher-education college in Israel. The training program is three years long and includes theoretical courses, courses on the teaching of various disciplines, and a practicum, which is conducted at a specific school, once a week throughout the three-year period. The first-year practicum of the student teachers in the current study was conducted in an elementary school, where they spent an entire day once a week for a period of two semesters (a total of 24 days of practicum). In that year, their practical assignments included planning a one-on-one lesson with a school student (by the end of the year, an additional pupil joined the lesson), carrying out the lessons they had planned, and receiving feedback about the lesson from the pedagogical counselor and from peers. In addition, the student-teachers conducted observations and met with other staff members to plan an educational activity at the school. The entire practicum, including all of its components, was documented in the form of a personal blog.

These blogs were not published for the perusal of Internet readers in general, but rather could be accessed only through the course website, featured on the college's online platform, a Modular Object-Oriented Dynamic Learning Environment (MOODLE). One of the reasons for keeping the blogs closed to the general public and open only to other members of the course had to do with maintaining the rules of ethics, so as not to reveal information about the school, the pupils, or the staff. At the same time, there was concern that publicizing the reflections of student-teachers would be detrimental to the practicum process. Course participants were asked to write a blog post once a week, reflecting on their specific experiences. Occasionally, photographs and video clips taken during the practicum, as well as links to other relevant websites, were also posted to their blogs.

In the current study, the focus is on two points in time in the course of the teacher-education program. The first point in time was during the participants' freshman-year practicum at an elementary school. In the course of that year, the researcher fulfilled the function of pedagogical counselor for this class of student-teachers and provided weekly feedback to their blog posts. The second point in time was towards the end of the participants' third and final year in the program, i.e., following three years of theoretical study and practical experience. In the course of the participants' third year, the researcher was not involved in any aspect of the group's learning or teaching experience. The researcher approached the original group towards the end of the second semester of their third year and asked them to participate in a study that required each of them to go back and reread their own blog, in which they had reflected on their first-year practicum experience. Next, each participant was interviewed 
and asked about the usefulness of keeping a blog in their first year of the program.

\section{Participants and Sampling}

Participants were 14 student-teachers who were completing their third year of the teacher-training program. All were women affiliated with the secular Jewish sector. Their ages ranged between 22 and 27 years, and they all had focused on preparing to teach at the elementary-school level. They taught a range of disciplines: five taught science classes, four taught math, three Bible studies, and two taught literature. Student-teachers in their first year of the program do not practice teaching in their particular discipline, but rather at this first stage, they all teach language arts; only in the second and third years of the program do they engage in a practicum involving their particular discipline. Participants were recruited through a convenience sampling method (Cohen et al., 2007; Creswell, 2005).

\section{Data Collection and Analysis}

The process of data collection for this study was conducted in two phases. In the first phase, the student-teachers were asked to return to the blog they had written in their freshman year using the college platform. In the second phase, the researcher conducted semi-structured interviews with each of the participants.

The interview questions referred to several aspects that could retrospectively shed light on the value of the blogging activity in the context of the teacher-education program. To ensure the participants' privacy as well as their understanding of the research in general, they all received an explanation regarding the study and its goals, and the anonymity of the participants (Cohen et al., 2007 ; Spradley, 1979); subsequently, they all indicated their willingness to participate. It is important to note that at the time of the study, the researcher was no longer acting as the pedagogical counselor to this group of students, had completed their evaluations two years earlier, and at the time of data collection had no other teaching relationship with the participants. In addition, the recruited student-teachers were told that they could choose whether or not to participate in the study and could withdraw at any time if they wished to do so. The study was approved by the ethics committee of the relevant college.

\section{Data Analysis}

Data were analyzed inductively, according to Richards (2009). The data retrieved were analyzed in two stages: in the first stage, a preliminary exploratory analysis was conducted, which included reading the transcribed 
interviews. Thus, a preliminary impression was formed and major themes were explored, taking into account possible organizational frameworks as well as the possibility that additional data might be needed. In the second stage, the interview transcripts were coded, so as to reveal major categories and subcategories or domains (Creswell, 2005).

\section{Results}

The interviews conducted with third-year student-teachers after they went back and reread the blog posts that they had written in their freshman year revealed three major ways in which the blog writing assignment had affected the teacher-education process, according to their retrospective views. Specifically, these participants found that the blog writing assignment was effective for the purposes of reflection, developing writing skills, and peer learning and sharing.

\section{Reflection}

Twelve of the 14 participants noted retrospectively that the blog provided a platform that helped advance their reflective and writing abilities. They especially emphasized that in the first year of their program, writing blog posts was a new and challenging type of assignment, one that they often times resented. However, in retrospect, they considered their reflective writing in the blog as an important basis for their current state of professional development.

Thanks to the reflective writing I did on the blog, I was able to gain important insights regarding my experience and my educational views, which were further developed and formed through the years. [of the program]. Although the reflective process was challenging at first, it soon became part of the routine, and helped me develop metacognitive reflection skills. At this point in time, I can clearly state that reflective analysis is an inseparable part of my experience and contributes to my ability to learn from experience, gain insights for future reference, and to pinpoint important issues that I wish to improve on or maintain. Most of all, it enables me to consider many aspects simultaneously.

Similarly, others noted, "Returning to the blog led me to understand the extent to which reflection was central to my learning and influenced my development process in a positive and significant manner;" and "The first-year blogging assignment served as a basis for the process I underwent. I think it was important in terms of reflective analysis, because by setting a firm basis, I was able to take it forward."

One of the participants described the link between the blogging activity and the development of her reflective abilities: 
I believe that reporting my thoughts through the blog helped me learn to express myself and formulate my thoughts intuitively, to process my feelings and the difficulties I encountered in various situations. Afterwards, I was able to think over the insights I had gained, consider alternatives, and suggest steps and changes. I think that the blog helped me develop my reflective abilities.

It appears that for the majority of the participants, the blogging was recognized as a significant tool for advancing reflective assessment skills. This finding coincides with those of other previous studies, which found that integrating blog writing in the course of teacher education can help develop reflective analysis (Deng \& Yuen, 2011; Harland \& Wondra, 2011).

\section{Writing Skills}

Twelve of the 14 participants noted retrospectively that the blogging assignment contributed to their motivation to write. On the one hand, this motivation was associated with the external aspect of a required assignment that formed part of the practicum: "In the first year, I found it difficult to write, but I knew I had to write blog posts as it was a requirement during the practicum." On the other hand, the motivation came from an inner source, such as the need for self-expression: "The blog motivated me to write because it enabled me to express myself in a manner that I chose and not in a prescribed way." Another participant noted, "I felt that the blog provided a format in which I could express my thoughts and feelings without holding back, knowing that whoever would read my posts would not be looking to critique them."

Some of the participants noted that the blog helped improve their writing skills; they associated this improvement with the fact that the writing was meant to address a familiar audience:

My writing skills improved significantly because of the blog. I reread my blog posts from the beginning of the first year and was amazed to find a poor vocabulary, spelling mistakes, and lack of proper punctuation, all of which posed a sharp contrast to my writing skills nowadays. I knew from the start that I would have to improve my writing and I knew I didn't want to feel embarrassed to let others read my posts.

Five of the participants claimed that that the blog writing assignment also helped them improve their academic writing skills, used in essays and assignments, and they associated this process with the development of language skills in general, which is an integral part of studying in an academic institution. "The more I wrote in the blog, the more my wording and language improved significantly. This, in and of itself, helped develop my academic writing skills and my ability to write academic papers in my various courses." These findings coincide with those of previous studies, 
which found that blogging helps promote writing skills among students in a teacher-education program (Biberman-Shalev, 2018; Kosnik et al., 2016).

\section{Peer Learning and Sharing}

Seven of the 14 participants noted retrospectively that for them the blog highlighted the importance of sharing as a preliminary step to peer learning. Thus, for example, "Through the blog. I learned the value of peer learning. Reading each other's blogs enabled us to open up to new ideas that we could try in the course of the practicum."

Everything that was posted to the blogs helped form our opinions, thoughts, and educational perceptions. This is one of the things that was very useful about the blog writing, especially if you felt stuck and needed a fresh idea for your lesson.

One of the student-teachers claimed that the blog was useful for peer learning, because it led her to understand that any event that took place in the course of the practicum could be examined from various points of view.

Sometimes, when I read a post written by someone else, I found that she had a different view of a particular event from our practicum and so she drew different conclusions. Sometimes reading such posts even changed my own perception of what had happened.

This finding is related to those of several studies that found that integrating blog writing in the teacher-education program helps promote a supportive learning community and creates a safe space for sharing knowledge and information (Duarte, 2015; Tang \& Lam, 2014).

\section{Discussion and Conclusion}

The use of blogs as part of the teacher-education process has been one of the foci of recent empiric studies which seek to improve the training process and adapt it to 21 st century requirements. In this context, the current study aimed to examine retrospectively the effectiveness of the blogging activity assigned to student-teachers in their first year of the program, in an effort to gain an in-depth understanding of its long-term impact on participants in the teacher-education program.

The findings of the study revealed student-teachers' retrospective perceptions of the type of impact that the blogging activity had on them, in the context of their training program, i.e., reflection, writing, and peer learning and sharing. The most frequently mentioned category was that of reflection. Upon returning to their blogs, participants were able to recognize that in their first year, they had not adequately understood the importance of reflection as a teaching practice; in fact, they had perceived it as an unnecessary burden. From the vantage point of a later point in their 
studies, they were able not only to identify the importance of this practice, but also to recognize that the blogging exercise assigned in their first year constituted a structural basis for developing and advancing this practice as part of their professional activity.

Some of the participants retrospectively perceived the blog was an activity that promoted the quality of their writing skills in general. Advancing writing skills is also related to external motivation, given that the blogging was a required assignment and that the posts were read by the pedagogic counselor and by peers. Furthermore, the writing was perceived also as an internal motivation, driven by the desire to express oneself and air the emotions that surfaced in the course of the practicum. These findings coincide with those of previous studies (Deng \& Yuen, 2011; Kosnik et al., 2016).

Another major aspect of the value of blogging as perceived retrospectively was the opportunity to learn and share with one's peers. Approximately half of the participants recognized retrospectively that the blogging activity led them to understand the importance of peer learning, and the advantages of sharing knowledge and information (Duarte, 2015; Morgan, 2015).

In summary, observing these findings and the vantage point provided by hindsight, it is possible to cautiously claim that a blogging activity that accompanies student-teachers' first year of practicum may serve as the basis for inculcating reflective thinking and writing and advancing writing skills in general. The implications of this conclusion are that blogs can have a long-term and valuable impact on the students in the teacher-education program. Another advantage of the blogging activity is that it enables student-teachers to experience first-hand the benefits of peer learning and sharing, which is brought into play when the exercising of certain skills takes place in cyberspace. These conclusions emphasize the important role of teacher educators. Teacher educators who integrate blogs during the first year of the program may provide a platform that helps establish a basis for practicing and improving both reflective practices and writing skills, which in turn leads students to understand the importance of reflection as an essential tool, practice their academic writing skills, and internalize the significance of peer learning and sharing.

It should be noted that the current study is not without limitations. First, the number of participants was relatively small and all participants were women. Second, it is possible that the participants' prior relationship with the researcher influenced their responses, despite the efforts to design the study in a manner that avoids such bias. Future studies could examine the impact of returning to the blog within shorter time intervals, for example, at the end of the first year of the teacher-education program, and then compare the impact of this retrospective activity at various stages. 


\section{References}

Biberman-Shalev, L. (2018). Personal blogs or communal blogs? Pre-service teachers' perceptions regarding the contribution of these two platforms to their professional development. Teaching and Teacher Education, 69, 253-262.

Chu, S. K. W., Chan, C. K. K., \& Tiwari, A. F. Y. (2012). Using blogs to support learning during internship. Computers and Education, 58(3), 989-1000.

Cohen, L., Manion, L., \& Morrison, K. (2007). Research methods in education (6 ${ }^{\text {th }}$ Ed.). Ney York, NY: Routledge.

Creswell, J.W. (2005). Educational research: Planning, conducting, and evaluating quantitative and qualitative research ( $3^{\text {rd }}$ Ed.). New Jersey: Pearson Merrill Prentice Hall.

Deng, L., \& Yuen, A. H. K. (2011). Towards a framework for educational affordances of blogs. Computers \& Education, 56, 441-451.

Duarte, P. (2015). The use of a group blog to actively support learning activities. Active Learning in Higher Education, 16(2), 103-117.

Flick, U. (2004) Design and process in qualitative research. In U. Flick, E. von Kardoff \& I. Steinke (Eds.), A companion to qualitative research (pp. 146-152). London: Sage.

Harland, D. J., \& Wondra, J. D. (2011). Preservice teachers' reflection on clinical experiences: A comparison of blog and final paper assignments. Journal of Digital Learning in Teacher Education, 27(4), 128-133.

Jones, M., \& Ryan, J. (2014). Learning in the practicum: Engaging pre-service teachers in reflective practice in the online space. Asia-Pacific Journal of Teacher Education, 42(2), 132-146.

Kirkwood, A., \& Price, L. (2014). Technology-enhanced learning and teaching in higher education: What is 'enhanced' and how do we know? A critical literature review. Learning, Media and Technology, 39(1), 6-36.

Kosnik, C., White, S., Marshall, B., Goodwin, A. L., \& Murray, J. (2016). Building bridges: Rethinking literacy teacher education in a digital era. The Netherlands: Sense Publishers.

Krishnamurthy, S. (2002). The multidimensionality of blog conversations: The virtual Enactment of September 11. Paper presented at Internet Research 3.0. Maastricht, The Netherlands.

Morgan, H. (2015). Creating a class blog: A strategy that can promote collaboration, motivation, and improvement in literacy. Reading Improvement, 52(1), 27-31.

Nambiar, R. M., \& Thang, S. M. (2016). Examining Malaysian teachers' online blogs for reflective practices: Towards teacher professional development. Language and Education, 30(1), 43-57.

Osman, G., \& Koh, J. H. L. (2013). Understanding management students' reflective practice through blogging. The Internet and Higher Education, 16, 23-31.

Petko, D., Egger, N., \& Cantieni, A. (2017). Weblogs in teacher education internships: Promoting reflection and self-efficacy while reducing stress? Journal of Digital Learning in Teacher Education, 33(2), 78-87.

Richards, L. (2009). Handling qualitative data: A practical guide ( $2^{\text {nd }}$ ed.). London: Sage.

Spradley, J. P. (1979). The ethnographic interview. Fort Worth, TX: Harcourt Brace Jovanovich College Publishers. 
Sim, J. W. S., \& Hew, K. F. (2010). The use of weblogs in higher education settings: A review of empirical research. Educational Research Review, 5(2), 151-163.

Stoszkowski, J., \& Collins, D. (2017). Using shared online blogs to structure and support informal coach learning-part 1: A tool to promote reflection and communities of practice. Sport, Education and Society, 22(2), 247-270.

Tang, E. (2013). The Reflective Journey of Pre-service ESL Teachers: An Analysis of Interactive Blog Entries. Asia-Pacific Educational Research, 22(4), 449-457.

Tang, E., \& Lam, C. (2014). Building an effective online learning community (OLC) in blog-based teaching portfolios. The Internet and Higher Education, 20, 79-85.

Top, E., Yukselturk, E., \& Inan, F. A. (2010). Reconsidering usage of blogging in pre-service teacher education courses. Internet and Higher Education 13(4), 214-217.

Xie, Y., Ke, F., \& Sharma, P. (2008).The effect of peer feedback for blogging on college students' reflective learning processes. Internet and Higher Education, 11, 18-25. 